\title{
Bidirectional Modulation of Insulin Action by Amino Acids
}

\author{
Mary-Elizabeth Patti, Eugenia Brambilla, Livio Luzi, Edwin J. Landaker, and C. Ronald Kahn
}

Research Division, Joslin Diabetes Center, and Division of Diabetes, Department of Medicine, Brigham and Women's Hospital, Harvard Medical School, Boston, Massachusetts 02215

\begin{abstract}
Amino acids have been shown to stimulate protein synthesis, inhibit proteolysis, and decrease whole-body and forearm glucose disposal. Using cultured hepatoma and myotube cells, we demonstrate that amino acids act as novel signaling elements in insulin target tissues. Exposure of cells to high physiologic concentrations of amino acids activates intermediates important in the initiation of protein synthesis, including p70 S6 kinase and PHAS-I, in synergy with insulin. This stimulatory effect is largely due to branched chain amino acids, particularly leucine, and can be reproduced by its transamination product, ketoisocaproic acid. Concurrently, amino acids inhibit early steps in insulin action critical for glucose transport and inhibition of gluconeogenesis, including decreased insulin-stimulated tyrosine phosphorylation of IRS-1 and IRS-2, decreased binding of grb 2 and the p85 subunit of phosphatidylinositol 3-kinase to IRS-1 and IRS-2, and a marked inhibition of insulinstimulated phosphatidylinositol 3-kinase. Taken together, these data support the hypothesis that amino acids act as specific positive signals for maintenance of protein stores, while inhibiting other actions of insulin at multiple levels. This bidirectional modulation of insulin action indicates crosstalk between hormonal and nutritional signals and demonstrates a novel mechanism by which nutritional factors contribute to insulin resistance. (J. Clin. Invest. 1998. 101:1519-1529.) Key words: insulin resistance • amino acids • ribosomal protein S6 kinase • 1-phosphatidylinositol 3-kinase • phosphoproteins/metabolism
\end{abstract}

\section{Introduction}

Previous metabolic studies have demonstrated that the ingestion of proteins or infusion of mixed amino acids has significant effects on both protein and glucose metabolism in normal human subjects. At a systemic level, amino acids stimulate insulin and glucagon secretion and increase endogenous glucose production (hepatic gluconeogenesis; reference 1). Amino acids have also been shown to directly stimulate protein synthesis, inhibit proteolysis, and enhance the sensitivity of protein

Address correspondence to C. Ronald Kahn, M.D., Research Division, Joslin Diabetes Center, 1 Joslin Place, Boston, MA 02215. Phone: 617-732-2635; FAX: 617-732-2593; E-mail: kahnr@joslab. harvard.edu

Received for publication 28 July 1997 and accepted in revised form 26 January 1998.

J. Clin. Invest.

(C) The American Society for Clinical Investigation, Inc. 0021-9738/98/04/1519/11 \$2.00

Volume 101, Number 7, April 1998, 1519-1529

http://www.jci.org synthesis to insulin (2-5). Branched chain amino acids, particularly leucine, play a particularly important role in mediating these protein anabolic and antiproteolytic effects of amino acids $(6,7)$.

In addition, amino acids, particularly the branched chain amino acids, also influence carbohydrate metabolism by decreasing glucose use in skeletal muscle $(8,9)$. The infusion of amino acids during a euglycemic hyperinsulinemic clamp in normal fasted volunteers decreases both whole body glucose oxidation and nonoxidative glucose disposal and forearm glucose disposal by up to $65 \%$ (10-15). Increased amino acid availability also decreases the sensitivity and magnitude of responsiveness to insulin action on hepatic glucose output (10).

In preliminary studies, we have demonstrated that the infusion of a balanced mixture of amino acids into chronically catheterized rats, under conditions in which euglycemia is maintained and endogenous insulin and glucagon secretion is inhibited, results in stimulation of p70 S6 kinase, a key intermediate in initiation of protein synthesis, in parallel with stimulation of protein synthesis and inhibition of proteolysis (16). To evaluate potential cellular mechanisms for the effects of amino acids to modulate insulin action on both protein and carbohydrate metabolism in vivo, we have studied the activation of key insulin signal transduction pathway intermediates by amino acids in isolated, cultured hepatoma cells and myocytes. We found that amino acids directly stimulate intermediates important in the initiation of protein synthesis, including p70 S6 kinase and PHAS-I phosphorylation, in synergy with insulin, while inhibiting steps in insulin action critical for glucose transport and inhibition of gluconeogenesis, such as insulin-stimulated IRS phosphorylation and activation of phosphoinositol 3-kinase (PI 3-kinase). ${ }^{1}$ These data support the hypothesis that amino acids can act as direct initiators of signal transduction pathways, as well as modifiers of insulin action at multiple levels.

\section{Methods}

Supplies and antibodies. Amino acid stocks were prepared using RPMI 1640 SelectAmine from GIBCO BRL (Gaithersburg, MD). Phosphoinositol was obtained from Avanti Polar Lipids (Alabaster, $\mathrm{AL}$ ). Electrophoresis supplies were from Bio-Rad Laboratories (Hercules, CA). All other supplies were from Sigma Chemical Co. (St. Louis, MO).

Antibodies used for immunoprecipitation and immunoblotting included: antiphosphotyrosine 4G10, anti-IRS-1 COOH-terminal, anti-p85-alpha (kindly provided by Dr. Morris White, Joslin Diabetes Center, Boston, MA), polyclonal anti-PI 3-kinase (Upstate Biotechnology, Inc., Lake Placid, NY), anti-p70 COOH terminus (AA 502-525, provided by Dr. Morris White), anti-ERK (provided by Dr. Bentley Cheatham, Joslin Diabetes Center, Boston, MA), anti-JNK

1. Abbreviations used in this paper: MAP, mitogen-activated protein; NIDDM, non-insulin-dependent diabetes mellitus; PI 3-kinase, phosphoinositol 3-kinase. 
(provided by Dr. John Kyriakis, Massachusetts General Hospital, Boston, MA), and anti-PHAS-I antibodies (provided by Dr. John Lawrence, Washington University School of Medicine, St. Louis, MO).

Cell culture and stimulation. FAO hepatocytes are grown to 80$90 \%$ confluence in RPMI 1640 with $10 \%$ FBS, fasted $12-18 \mathrm{~h}$ in serum-free medium with $0.5 \%$ insulin-free BSA, and subjected to amino acid deprivation for $1 \mathrm{~h}$. The culture medium was replaced with the amino acid-free medium with or without $100 \mathrm{nM}$ insulin or an isosmolar mixture of amino acids (measured osmolarity 300-310 $\mathrm{mOsm} / \mathrm{kg}$ ). For all experiments, cells that were subjected to amino acid deprivation alone (for $1 \mathrm{~h}$ plus the duration of the corresponding treatment period, usually $30 \mathrm{~min}$ ) are labeled as basal. Unstimulated p70 S6 kinase activity in cells subjected to overnight fast and $1 \mathrm{~h}$ of amino acid deprivation did not differ significantly from that of cells subjected to an overnight serum deprivation alone. The concentration of each amino acid used for cell stimulation is expressed as the multiple of its concentration in the portal vein of a fasted rat (17). The concentration of amino acids in a $1 \times$ mixture is as follows: alanine, $400 \mu \mathrm{M}$; arginine, $100 \mu \mathrm{M}$; asparagine, $60 \mu \mathrm{M}$; aspartate, $30 \mu \mathrm{M}$; cysteine, $60 \mu \mathrm{M}$; glutamic acid, $100 \mu \mathrm{M}$; glutamine, $350 \mu \mathrm{M}$; glycine, $300 \mu \mathrm{M}$; histidine, $60 \mu \mathrm{M}$; isoleucine, $100 \mu \mathrm{M}$; leucine, $250 \mu \mathrm{M}$; lysine, $300 \mu \mathrm{M}$; methionine, $40 \mu \mathrm{M}$; phenylalanine, $50 \mu \mathrm{M}$; proline, $100 \mu \mathrm{M}$; serine, $200 \mu \mathrm{M}$; threonine, $180 \mu \mathrm{M}$; tryptophan, $70 \mu \mathrm{M}$; tyrosine, $75 \mu \mathrm{M}$; and valine, $180 \mu \mathrm{M}$.

At the end of the stimulation period (5-120 min), cells were washed twice with STE $(150 \mathrm{mM} \mathrm{NaCl}, 50 \mathrm{mM}$ Tris, $1 \mathrm{mM}$ EDTA, $\mathrm{pH} 7.2)$ and lysed in extraction buffer $\left(10 \mathrm{mM} \mathrm{KPO}_{4} / 1 \mathrm{mM}\right.$ EDTA, $5 \mathrm{mM}$ EGTA, $10 \mathrm{mM} \mathrm{MgCl} 2,50 \mathrm{mM}$ B-glycerophosphate, $2 \mathrm{mM}$ vanadate, $0.5 \% \mathrm{NP}-40,0.1 \% \mathrm{Brij}, 10 \mu \mathrm{g} / \mathrm{ml}$ leupeptin, $10 \mu \mathrm{g} / \mathrm{ml}$ aprotinin, $1 \mathrm{mM}$ benzamidine, and $2 \mathrm{mM}$ PMSF, $\mathrm{pH}$ 7.2). Cell lysates were clarified by centrifugation at $10,000 \mathrm{~g}$ for $15 \mathrm{~min}$. In some studies, cells were pretreated with the inhibitors wortmannin (1-100 nM), rapamycin $(0.25-25 \mathrm{ng} / \mathrm{ml})$, or PD $98059(50 \mu \mathrm{M})$ for $10 \mathrm{~min}$ before stimulation with insulin and/or amino acids.

Additional experiments were performed in hep G2 hepatocytes and L6 myotubes.

p70 S6 kinase assays. Supernatants containing $300 \mu \mathrm{g}$ of protein were immunoprecipitated with a polyclonal antibody raised against the $\mathrm{COOH}$ terminus of p70 S6 kinase (AA 502-525). Immune complexes were collected with protein A-Sepharose and washed. In vitro S6 kinase assays were performed as described (18) using $5 \mu \mathrm{g}$ of GST-S6 fusion protein as substrate. Reaction products were separated by $10 \%$ SDS-PAGE; gels were stained with Coomassie to verify equality of sample loading and dried. Incorporation of ${ }^{32} \mathrm{P}$ into GST-S6 peptide was quantitated with a PhosphorImager (Molecular Dynamics, Sunnyvale, CA).

For gel shift assays, aliquots of cell lysate supernatants $(25 \mu \mathrm{g}$ protein) were solubilized in Laemmli sample buffer, separated by $10 \%$ SDS-PAGE, transferred to nitrocellulose, and immunoblotted with anti-p70 antibodies. Bands were visualized by ECL.

PHAS-I phosphorylation assays. $25 \mu \mathrm{g}$ of solubilized cell lysates were separated by $12 \%$ SDS-PAGE, transferred to nitrocellulose, and immunoblotted with an anti-PHAS-I antibody (kindly provided by Dr. John Lawrence). Bands were visualized with ECL.

PI 3-kinase assays. Cell lysate supernatants containing $300 \mu \mathrm{g}$ of protein were immunoprecipitated with the monoclonal antibody antiphosphotyrosine 4G10 or anti-p85- $\alpha$ antibodies; immune complexes were collected with protein A-Sepharose and washed extensively as described previously (19). In vitro kinase assays were performed using phosphoinositol as an in vitro substrate. ${ }^{32} \mathrm{P}$ incorporation into PI 3-phosphate was quantified using a PhosphorImager.

For determination of total cellular phospholipids, quiescent cells were labeled with ${ }^{32} \mathrm{P}$ for $2 \mathrm{~h}$ before addition of insulin and/or amino acids. At the end of the stimulation period, lipids were extracted in acidified $\mathrm{CHCl}_{3}$, deacylated, and subjected to HPLC analysis with labeled standards.

ERK and JNK assays. Supernatants containing $300 \mu \mathrm{g}$ of protein were immunoprecipitated with anti-ERK antibody or anti-JNK anti- body and washed extensively. In vitro kinase assays were performed, using myelin basic protein or GST-cJun 1-135 as substrates, respectively (20). ${ }^{32} \mathrm{P}$ incorporation into substrate was quantified using a PhosphorImager.

Western blotting. Immunoprecipitates or cell lysates were solubilized in Laemmli sample buffer, separated by SDS-PAGE, and transferred to nitrocellulose. Immunoblotting was performed as described previously (19). Electrophoretic mobility shift assays using anti-p70 S6 kinase antibodies or anti-PHAS-I antibodies were visualized by ECL, while all other immunoblots were visualized by ${ }^{125}$ I-protein A and quantitated by PhosphorImager.

Mitogenesis assay. Fao cells at $80-90 \%$ confluence in triplicate wells were fasted for $24 \mathrm{~h}$ in RPMI 1640 with $0.1 \%$ BSA and $25 \mathrm{mM}$ Hepes, $\mathrm{pH}$ 7.4. Cells were then stimulated with serum, insulin, amino acids, or insulin plus amino acids for a total of $18 \mathrm{~h}$, with one change of medium. $\left[{ }^{3} \mathrm{H}\right]$ thymidine was added for a 1 -h incubation period in a $37^{\circ} \mathrm{C}$ water bath. Cells were washed with PBS three times and solubilized with $0.1 \%$ SDS; proteins were precipitated with TCA, collected on glass fiber filters, and counted. Data are expressed as percentage of serum-stimulated values.

Statistical analysis. Results are indicated as mean \pm SEM for all data. Paired Student's $t$ tests were used for analysis of differences between cell stimuli. $P$ values $<0.05$ are considered significant.

\section{Results}

Amino acids activate p70 S6 kinase in vitro. p70 S6 kinase is a serine/threonine kinase activated in response to insulin and other growth factors and responsible for phosphorylation of ribosomal protein S6 in vivo (21). Our data from in vivo studies in chronically catheterized rats have demonstrated that amino acid infusion stimulates the activation of p70 S6 kinase, in parallel with stimulation of protein synthesis and inhibition of proteolysis (16). To explore these findings in the absence of complicating systemic hormonal changes, well-differentiated cultured hepatoma cells (Fao) were stimulated with a mixture of amino acids equal to four times the concentration found in the portal vein of a fasted rat (designated as $4 \times$ amino acids), and the effect on p70 S6 kinase activity and phosphorylation was assessed. As seen in Fig. $1 A$, amino acids stimulated the activation of p70 S6 kinase by twofold $(P<0.001)$ over basal, as determined in an immune complex kinase assay using a GST-S6 peptide as substrate. The magnitude of stimulation by amino acids was comparable to that induced by insulin (2.2fold, $P<0.001$ ), while the addition of amino acids to insulin resulted in an additive effect (3.5-fold above basal, $P<0.001)$. The activation of p70 S6 kinase is accompanied by an increase in serine phosphorylation that results in a more retarded mobility of the enzyme on SDS-PAGE. Both amino acids and insulin induced a similar retardation in mobility of p70 S6 kinase in SDS-PAGE, which was maximal at $30 \mathrm{~min}$ (Fig. $1 \mathrm{~B}$ ). Amino acids also stimulated the phosphorylation of both cytoplasmic (p70) and nuclear (p85) S6 kinase isoforms in hep G2 cells and stimulated the activity of p70 S6 kinase in L6 myotubes 1.9 -fold ( $P=0.03$ versus basal, data not shown). These effects were time dependent, peaking at $30 \mathrm{~min}$ (data not shown), and concentration dependent (Fig. 1C). p70 S6 kinase activity increased progressively as fasted cells were treated with increasing concentrations of equimolar amino acid mixtures ranging from 0.5 to $4 \times(14 \%$ increase for $1 \times, P<0.001$, $69 \%$ increase for $2 \times, P=0.001)$.

Amino acid stimulation of p70 S6 kinase is rapamycin- and wortmannin-dependent. The phosphorylation-dependent activation of p70 S6 kinase by insulin and other growth factors 


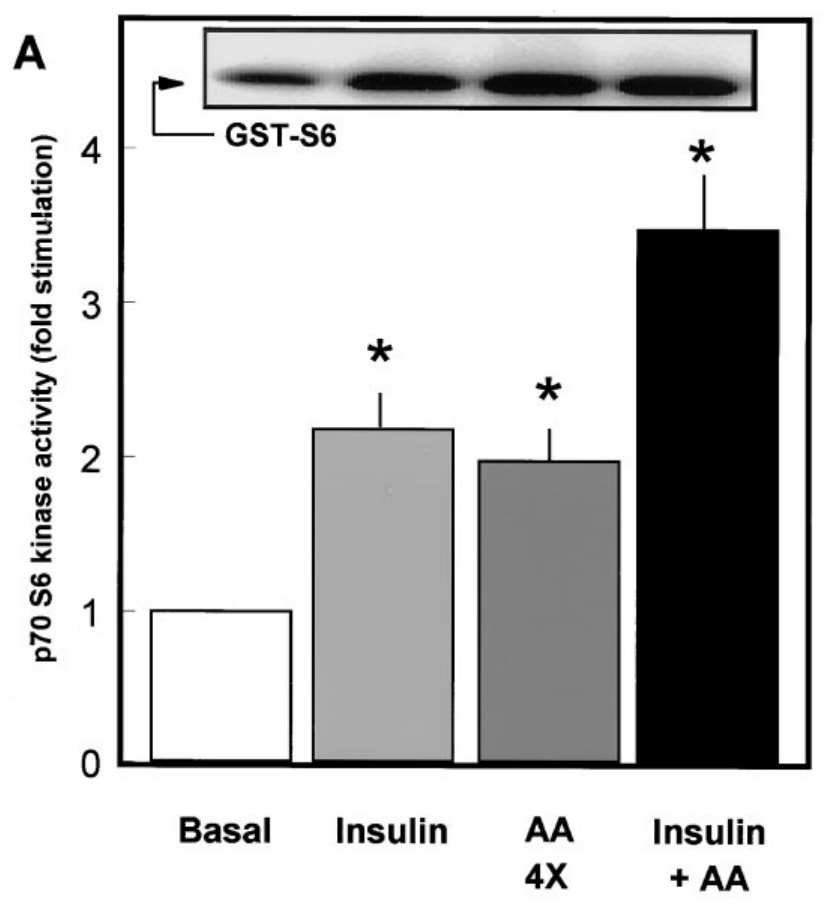

B

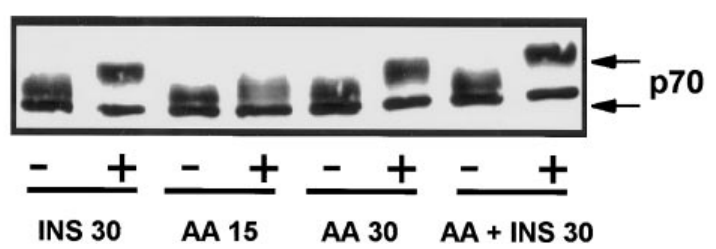

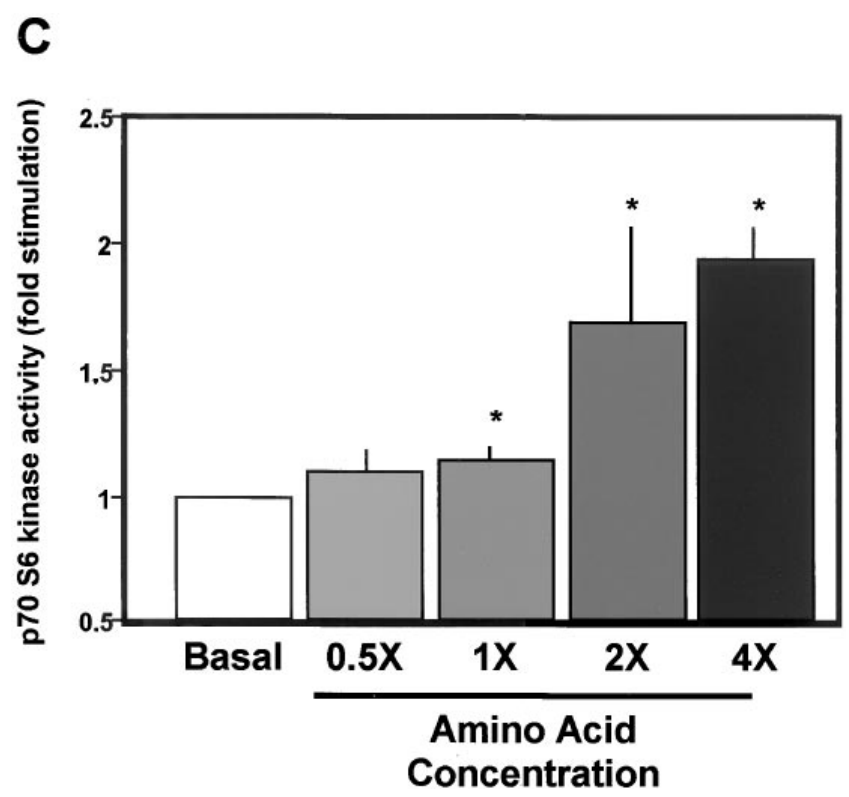

Figure 1. Amino acids stimulate p70 S6 kinase activity. Fao hepatocytes were cultured as described, fasted $12-18 \mathrm{~h}$, and subjected to amino acid deprivation for $1 \mathrm{~h}$. The culture medium was replaced with the amino acid-free medium with or without $100 \mathrm{nM}$ insulin or an isosmolar mixture of amino acids, as described in Methods. After the stimulation period, cells were lysed; supernatants were processed for immune complex kinase assays or gel mobility shift assays. $(A)$ Quantitative results of p70 immune complex kinase assays in Fao cells stimulated with $100 \mathrm{nM}$ insulin, the complete amino acid mixture $(4 \times)$, or both. Data are summarized from 13 independent experiments and are expressed as fold stimulation above basal (amino acid deprivation alone; mean \pm SEM) following a 30 min stimulation period. $* P<0.001$ versus basal. The inset shows representative gel from p70 S6 kinase immune complex assay demonstrating incorporation of ${ }^{32} \mathrm{P}$ into GST-S6 peptide substrate in lysates from cells treated with amino acids and/or insulin for $30 \mathrm{~min}$. $(B)$ Representative p70 S6 kinase gel mobility shift assay: $25 \mu \mathrm{g}$ of cell lysates were separated by $10 \%$ SDS-PAGE and immunoblotted with anti-p70 S6 kinase antibody with ECL visualization. Indicated below individual lanes are stimulus and duration $(\mathrm{min})$ of stimulation period. $(C)$ Concentration dependence of amino acid effect on p70 S6 kinase activity. Cells were stimulated with equimolar amino acid mixtures ranging in concentration from 0.5 to $4 \times$. $* P \leq 0.001$ versus basal. Data are from three independent experiments for dose-response analysis.

can be inhibited by the macrolide rapamycin, via its interaction with its cytosolic receptor FKBP12 and inhibition of mTor (22). The activation of p70 S6 kinase is also inhibited by wortmannin and LY294004, two unrelated inhibitors of the enzyme PI 3-kinase, suggesting that p70 S6 kinase lies downstream of PI 3-kinase (23), mTor, or another kinase sharing a related catalytic domain (24). To determine if rapamycin- and wortmannin-dependent pathways were involved in the activation of p70 S6 kinase by amino acids, cells were pretreated with rapamycin or wortmannin for $10 \mathrm{~min}$ before stimulation with insulin and/or amino acids. As seen in Fig. 2, rapamycin inhibited the ability of both insulin and amino acids to stimulate p70 activation, as determined both by immune complex kinase assays (Fig. $2 A$ ) and the gel mobility shift assay (Fig. $2 B$ ). This effect was dose dependent, and could be observed with concentrations as low as $0.25 \mathrm{ng} / \mathrm{ml}$ of rapamycin. Wortmannin also abolished the activation of p70 S6 kinase activity by amino acids, with a magnitude comparable to its effect on insulinstimulated kinase activation (Fig. 2, $A$ ). This inhibition by wortmannin was dose dependent, with maximal inhibition at concentrations of $10-50 \mathrm{nM}$ (Fig. 2 C). This is similar to the concentration dependence for wortmannin inhibition of PI 3-kinase but lower than the concentrations required for maximal inhibition of mTor autokinase activity (24). Taken together, these data indicate that both rapamycin- and wortmannin-sensitive pathways are required for the stimulation of $\mathrm{p} 70$ S6 kinase by amino acids; this pattern suggests a requirement for both mTor and other wortmannin-sensitive kinases, including PI 3-kinase.

Amino acids do not activate Akt/protein kinase B. Akt, which is also known as protein kinase B or Rac, is a serine/ threonine kinase localized downstream of PI 3-kinase which may play a role in the activation of p70 S6 kinase by insulin and other growth factors $(25,26)$. To assess the role of this pathway, we used the gel mobility shift assay, since this correlates with direct measurements of enzyme activity (26). In Fao cells, insulin induced a gel mobility shift, indicating activation of this enzyme (Fig. 3). By contrast, however, amino acids alone had no effect on Akt phosphorylation, nor did they modify the insulin effect. We conclude, therefore, that the effect of 
A
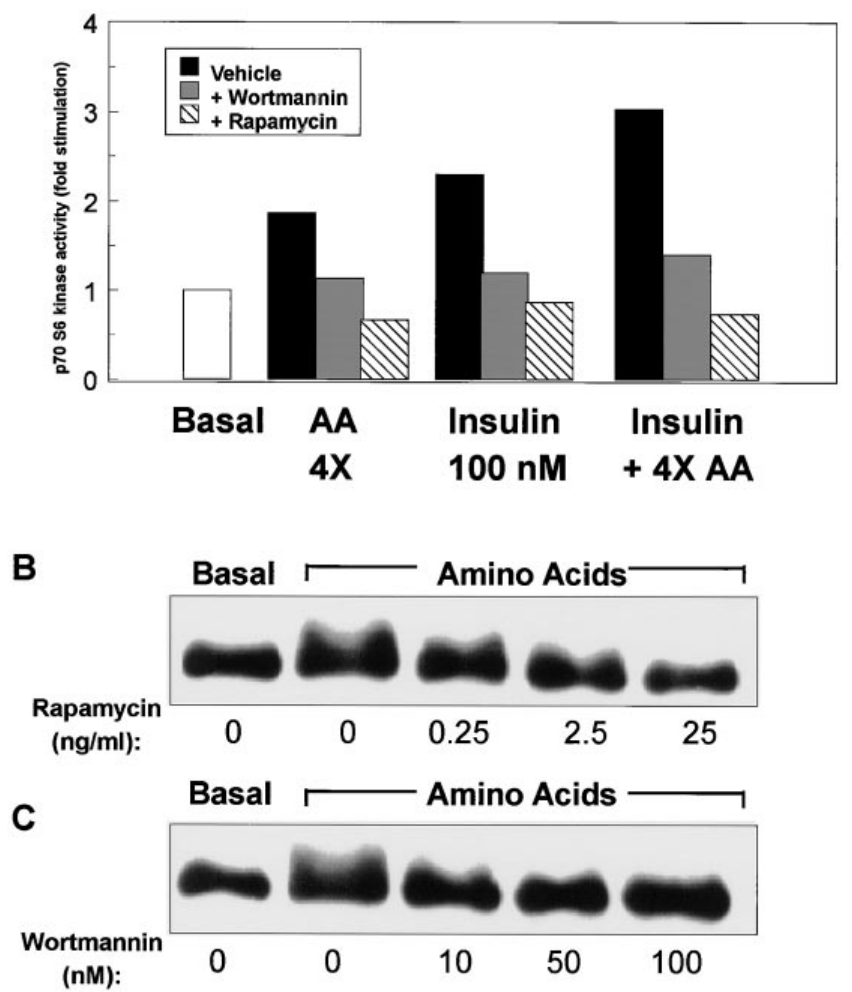

Figure 2. The stimulation of p70 S6 kinase activity by both amino acids and insulin involves rapamycin- and wortmannin-dependent pathways. $(A)$ Quantitative results from p70 immune complex kinase assays in Fao cells stimulated for 30 min with the complete amino acid mixture, $100 \mathrm{nM}$ insulin, or both after $10 \mathrm{~min}$ of pretreatment with vehicle (Basal), rapamycin $(25 \mathrm{ng} / \mathrm{ml})$, or wortmannin $(50 \mathrm{nM})$. Data are expressed as fold stimulation above basal and are representative of two independent experiments. $(B)$ Representative gel mobility shift assay demonstrating dose-dependent inhibitory effect of rapamycin on stimulation of p70 S6 kinase phosphorylation by amino acids. $(C)$ Representative gel mobility shift assay demonstrating dosedependent inhibitory effect of wortmannin on p70 S6 kinase phosphorylation.

amino acids on p70 S6 kinase is mediated by an Akt-independent pathway.

Amino acids stimulate the phosphorylation of PHAS-I. The phosphorylation of PHAS-I (4E-BP-1) in response to growth factors, including insulin, results in its dissociation from the eIF-4E complex, allowing the efficient initiation of translation, particularly of mRNA containing polypyrimidine tracts (27). In Fao cells, three dominant phosphorylated forms of PHAS-I $(\alpha, \beta$, and $\gamma$ ) were detected in the basal state (Fig. 4 $A)$. Both amino acids and insulin stimulated a shift in mobility to the more highly phosphorylated $\beta$ and $\gamma$ forms, with a maximum effect of amino acids occurring at $30 \mathrm{~min}$. As with the p70 S6 kinase phosphorylation, the addition of amino acids to insulin produced an additive effect on PHAS-I phosphorylation such that almost all of the enzyme was in the $\gamma$-hyperphosphorylated state.

The phosphorylation of PHAS-I by insulin has been shown to be rapamycin- and wortmannin-sensitive but mitogen-activated protein (MAP) kinase independent $(24,28)$. To deter-

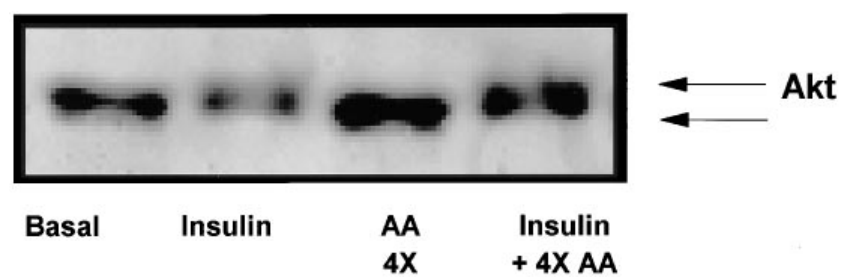

Figure 3. Amino acids do not stimulate phosphorylation of Akt. 50 $\mu \mathrm{g}$ lysates of Fao cells stimulated with insulin and/or amino acids for 30 min were separated by SDS-PAGE, immunoblotted with anti-Akt antibody, and visualized by ECL. The gel retardation of Akt induced by insulin, but not by amino acids, is indicated by the arrows. Blots are representative of two independent experiments.

mine if these same regulatory patterns applied to the stimulation of PHAS-I by amino acids, cells were pretreated with rapamycin, wortmannin, or the MEK inhibitor PD98059. Rapamycin blocked the activation of PHAS-I phosphorylation by both amino acids and insulin. (Fig. $4 A$ ). Similarly, wortmannin inhibited PHAS-I phosphorylation (data not shown). In contrast, pretreatment of cells with PD98059 had no effect on the stimulation of PHAS-I phosphorylation by either amino acids or insulin (Fig. $4 \mathrm{~B}$ ). Taken together, these data suggest a requirement for mTor and wortmannin-sensitive kinases, but not MEK-dependent pathways, in the stimulation of both PHAS-I and p70 S6 kinase by amino acids.

Amino acids do not stimulate the activation of MAP or c-Jun kinases. The ERK family of MAP kinases has been implicated in regulation of gene expression, while c-Jun/stress-activated protein (JNK/SAP) kinases are involved in cellular re-
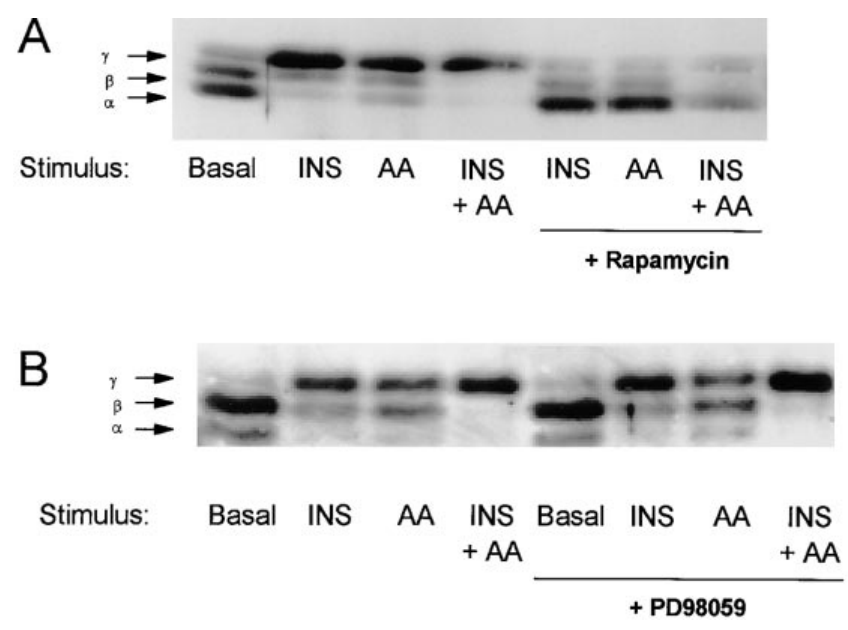

Figure 4. Amino acids and insulin stimulate phosphorylation of PHAS-I. ( $A$ ) Lysates of Fao cells stimulated with insulin and/or amino acids for 30 min were separated by SDS-PAGE, immunoblotted with anti-PHAS-I antibody, and visualized by ECL. Both insulin and amino acids induce a shift from the less phosphorylated $\alpha$ to the more heavily phosphorylated $\beta$ and $\gamma$ isoforms. Pretreatment of cells with rapamycin $(25 \mathrm{ng} / \mathrm{ml})$ for $10 \mathrm{~min}$ before stimulation with insulin and/or amino acids inhibited the mobility shift. $(B)$ Pretreatment of cells with the MEK inhibitor PD $98059(50 \mu \mathrm{M})$ for 10 min before stimulation did not inhibit the mobility shift induced by either insulin and/or amino acids. Blots are representative of two independent experiments. 


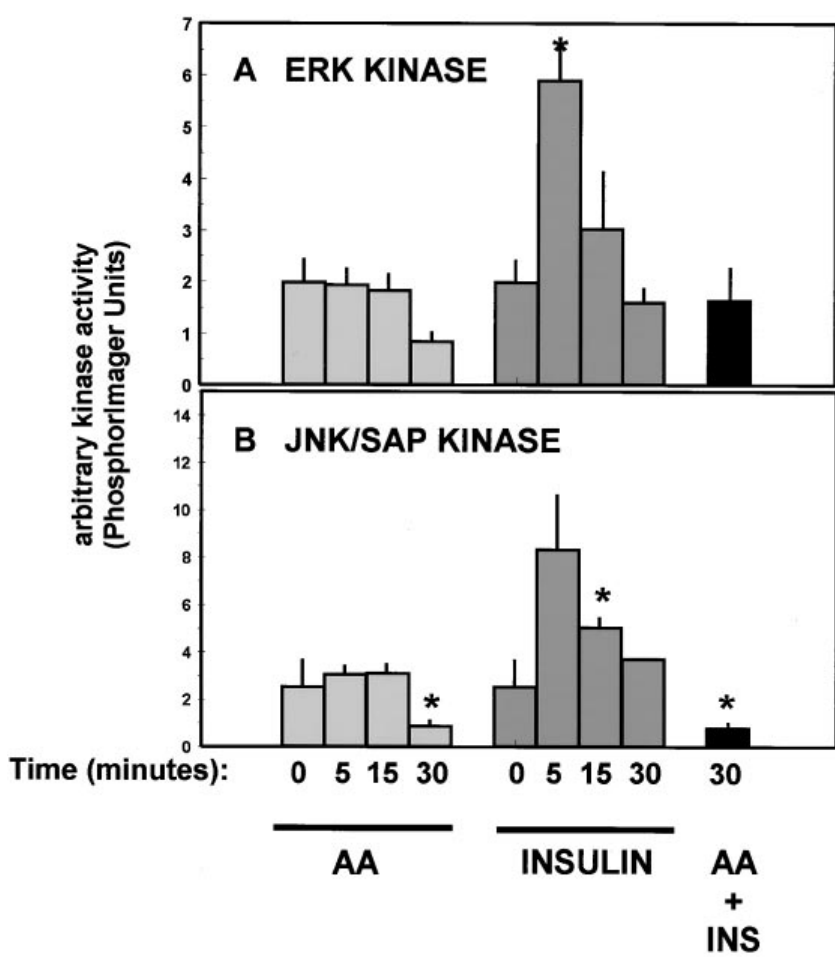

Figure 5. Amino acids do not activate ERK or JNK kinases. Fao cells were stimulated with the complete $4 \times$ mixture of amino acids, $100 \mathrm{nM}$ insulin, or both for the indicated time ( $\mathrm{min})$. Cell lysates were immunoprecipitated with anti-ERK $(A)$ or anti-JNK $(B)$ antibodies; activity was assessed in an immune complex kinase assay using myelin basic protein or GST-c-Jun peptide as substrate, respectively. Data are expressed as arbitrary PhosphorImager units. For comparison, the activation of JNK by cycloheximide yielded an activity level of 68 PhosphorImager units (data not shown). $* P<0.05$ versus basal (time 0).

sponses to osmotic and other cellular stresses (20). To assess the potential role for activation of these two pathways in mediating the effect of amino acids, immune complex kinase assays were performed in anti-ERK or anti-JNK immunoprecipitates. As seen in Fig. $5 A$, insulin is a potent stimulus for rapid ERK activation. In contrast, amino acids do not stimulate the activity of ERK 1 or 2. Similarly, amino acids did not stimulate the activation of c-Jun kinase, in contrast to the twofold stimulation by insulin at $15 \mathrm{~min}(P=0.01$, Fig. $5 B)$ and the marked stimulation by cycloheximide (27-fold, data not shown). Rather, amino acids inhibited activation of c-Jun kinase by $65 \%$ at $30 \mathrm{~min}$ and inhibit the modest insulin effect. Thus, amino acids do not activate protein kinase cascades globally nor are their effects mediated by activation of a common cellular or osmotic stress pathway.

Branched chain amino acids are largely responsible for the stimulatory effect of amino acids on p70 S6 kinase activation. Branched chain amino acids play a dominant role in mediating stimulation of protein synthesis and inhibition of proteolysis $(6,17,29,30)$. To evaluate the role of different groups of amino acids and different amino acid transport systems in the stimulation of p70 S6 kinase activity, cells were stimulated with the complete mixture of amino acids (Fig. $6 A$ ) or mixtures of amino acids of equal total molarity. These included groups of amino acids that use the ASC, A, or L transport systems, the branched chain amino acids, or a mixture (leucine, tyrosine, and phenylalanine) previously found to stimulate S6 phosphorylation in hepatocytes (17). The stimulatory effect of the complete amino acid mixture could be largely reproduced by a mixture of amino acids containing either the branched chain amino acids (leucine, isoleucine, and valine) or a mixture of leucine, phenylalanine, and tyrosine (Fig. $6 \mathrm{~B}$ ) but not by the ASC, A, or L groups. Of the stimulatory amino acids, leucine was dominant in mediating the activation of p70 S6 kinase (Fig. $6 \mathrm{C}$ ), even in concentrations as low as $250 \mu \mathrm{M}$. Despite the dominant effect of leucine, there was a permissive effect of all other amino acids, as indicated by the additive effect of a $1 \times$ mixture of all other amino acids (Fig. $6 D$ ). In addition, ketoisocaproic acid, the product of leucine transamination, was similarly effective in stimulating p70 S6 kinase activity (Fig. 6D).

Amino acids inhibit early events in insulin signaling. Previous metabolic studies have demonstrated that amino acids inhibit the action of insulin to stimulate glucose transport in vivo (10-15). Given the critical role of PI 3-kinase in mediating insulin-stimulated glucose transport $(23,31)$, inhibition of gluconeogenesis and expression of phosphoenolpyruvate carboxykinase (32), and glycogen synthesis (33), we evaluated the effect of amino acids on this enzyme pathway. As seen in Fig. $7 A$, insulin is a potent stimulus for PI 3-kinase activation in both antiphosphotyrosine and anti-p85- $\alpha$ immunocomplexes. By contrast, amino acids, at concentrations that maximally stimulate p70 S6 kinase, did not stimulate PI 3-kinase. To explore the possibility that 3-phosphorylated lipid products were generated by amino acid stimulation but not detected using the immune complex kinase assay, total cellular lipids were extracted from ${ }^{32} \mathrm{P}$-labeled Fao cells, deacylated, and separated via HPLC analysis. Again, these assays revealed no increase in 3-, 3,4-, or 3,4,5-phospholipids after amino acid stimulation.

Not only did amino acids fail to stimulate PI 3-kinase, amino acids actually inhibited insulin-stimulated PI 3-kinase activity. In antiphosphotyrosine precipitates, insulin-stimulated PI 3-kinase activation was reduced by $76 \%(P<0.05)$. In anti-p85 precipitates, insulin-stimulated PI 3-kinase activation was reduced by $53 \%$ (Fig. $7 \mathrm{~A}$ ). Since PI 3-kinase activation is required for insulin-stimulated glucose transport in insulin-sensitive tissues $(34,35)$, we also evaluated the effect of amino acids on PI 3-kinase activity in L6 myotubes. Amino acids inhibited insulin-stimulated phosphotyrosine-associated PI 3-kinase by $68 \%(P<0.001$, Fig. $7 \mathrm{~B})$.

The activation of the catalytic domain of PI 3-kinase by insulin requires the interaction of the $\mathrm{SH} 2$ domains of the $\mathrm{p} 85$ regulatory subunit of PI 3-kinase with phosphotyrosine residues on cytoplasmic insulin receptor substrate proteins such as IRS-1, IRS-2, and Gab-1. Therefore, we examined changes in tyrosine phosphorylation of cellular proteins after stimulation with amino acids. As seen in antiphosphotyrosine immunoblots (Fig. $8 \mathrm{~A}$ ), insulin stimulated the tyrosine phosphorylation of the $\beta$-subunit of the insulin receptors, IRS-1 and IRS-2, which appear as bands of MW 95, 180, and $185 \mathrm{kD}$. By contrast, amino acids did not alter tyrosine phosphorylation of proteins ranging from 50-200 kD. Likewise, amino acids had no effect on tyrosine phosphorylation of proteins with a molecular mass of $15-50 \mathrm{kD}$ (data not shown). However, the addition of amino acids to insulin did result in a modest inhibition of insulin-stimulated tyrosine phosphorylation of high molecu- 


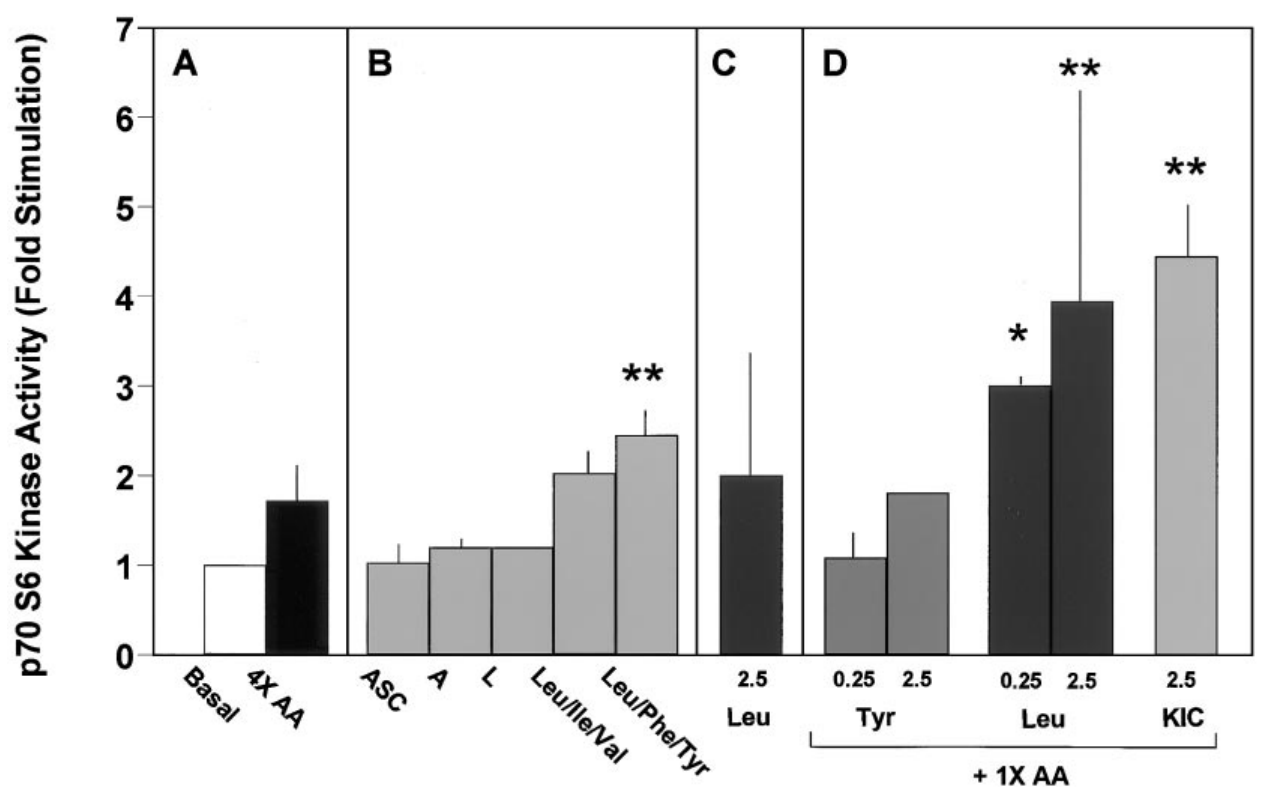

Figure 6. Branched chain amino acids are largely responsible for the effect of amino acids to stimulate p70 S6 kinase. The complete $4 \times$ mixture $(11.6 \mathrm{mM} ; A)$ or equimolar mixtures of amino acids $(B)$, grouped according to major transport mechanisms or other characteristics, were used to stimulate Fao cells for $30 \mathrm{~min}$ before cell lysis and processing for $\mathrm{p} 70$ immune complex kinase assay. The amino acid groups are as follows: ASC-alanine, cysteine, threonine, asparagine, glutamine, serine; A-proline, glycine; L-methionine, phenylalanine, leucine, isoleucine, valine, and histidine. The total amino acid molarity of these groups was $11.6 \mathrm{mM}$. To evaluate the role of specific amino acids, cells were stimulated with the indicated concentration of the individual amino acid without $(C)$ or with $(D)$ the $1 \times$ complete mixture. $\mathrm{NaCl}$ was added as needed to maintain equal osmolarity. Data are expressed as fold stimulation above basal and are means from three independent experiments. ${ }^{*} P<0.05$ versus basal (unstimulated); ${ }^{* *} P<0.01$ versus basal.

A

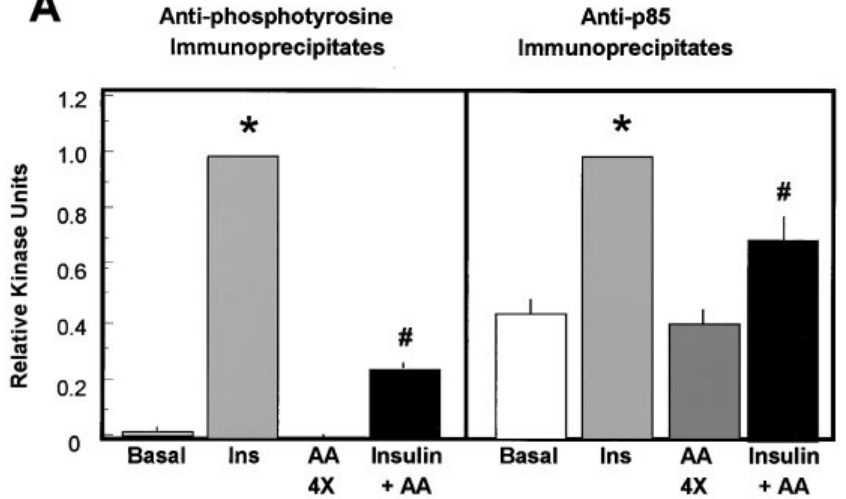

B

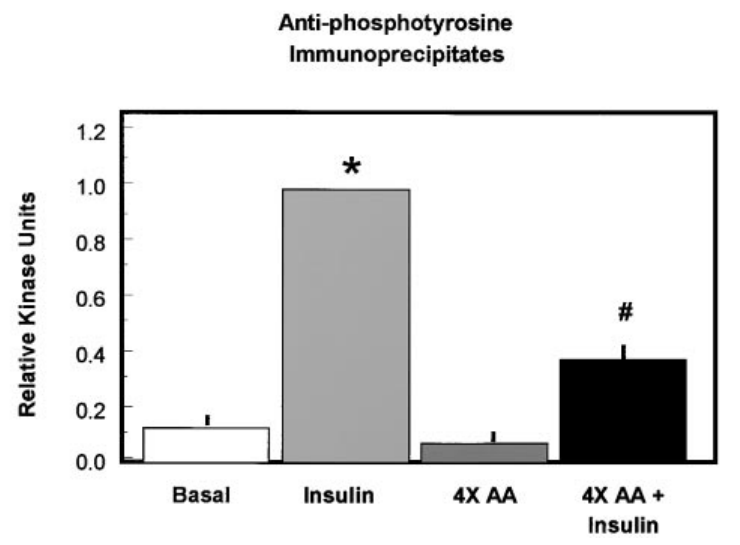

Figure 7. Amino acids do not stimulate PI 3-kinase activity directly, but inhibit insulin-stimulated PI 3-kinase activity. $(A)$ Fao cells were stimulated with insulin and/or amino acids for $30 \mathrm{~min}$. Kinase assays were performed on antiphosphotyrosine or anti-p85- $\alpha$ immunoprecipitates using phosphatidylinositol as an in vitro substrate. Data are expressed as relative PhosphorImager units (mean \pm SEM). ${ }^{*} P<0.01$ lar weight insulin receptor substrates (Fig. 8 B). Quantitation of multiple experiments by scanning densitometry revealed that the decrease averaged $44 \%$ (Fig. 8 C). When IRS-1 was specifically analyzed by immunoprecipitation, amino acids decreased insulin-stimulated tyrosine phosphorylation by $48 \%$ $(P<0.01$; Fig. $9, A$ and $B[B$, left panel $])$. This resulted in a decrease in the association of IRS- 1 with both the $\mathrm{p} 85$ regulatory subunit of PI 3-kinase by $38 \%(P=0.01$; Fig. 9 B, center panel) and the adapter protein Grb2 by $76 \%$ (Fig. $9 \mathrm{~B}$, right panel). The tyrosine phosphorylation of IRS-2 and its association with p85 and Grb2 was also reduced when amino acids were added to insulin (data not shown). This reduction in phosphorylation of insulin receptor substrates involves postreceptor mechanisms, as no reproducible change in insulin receptor phosphorylation was observed (Fig. 8 B).

Amino acids inhibit insulin-stimulated mitogenesis. Since amino acids inhibit early events in insulin signaling, including activation of PI 3-kinase, an enzyme implicated in control of mitogenesis (36), we evaluated the effects of amino acids on insulin-stimulated thymidine incorporation in Fao cells. As seen in Fig. 10, insulin produced a modest increase in mitogenesis over the 18 -h stimulation period (47\% increase for $100 \mathrm{nM}$ insulin, $P<0.05)$. Amino acids alone had no effect on basal mitogenesis, but potently inhibited the effect of insulin $(65 \%$ decrease in thymidine incorporation as compared with insulin alone, $P<0.001)$.

versus basal. ${ }^{\#} P<0.01$ versus insulin alone. (B) L6 myotubes were stimulated with insulin and/or amino acids for $30 \mathrm{~min}$; PI 3-kinase assays were performed as for Fao cells. $* P<0.001$ versus basal; ${ }^{\#} P<$ 0.001 versus insulin-stimulated cells. Data are the mean of duplicate assays in two independent experiments. 
A

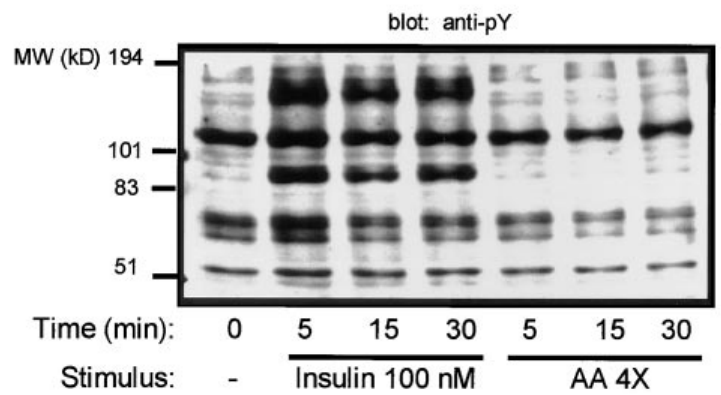

B

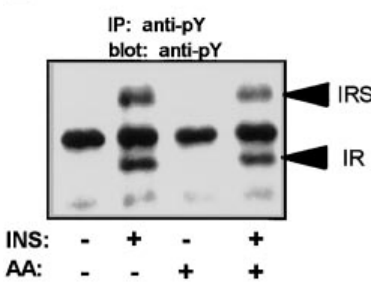

C

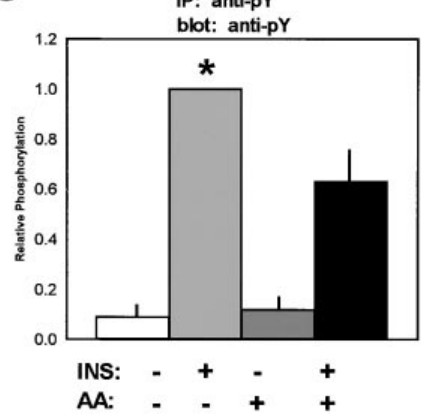

Figure 8. Amino acids do not stimulate tyrosine phosphorylation of intracellular proteins $(A)$ but inhibit insulin-stimulated phosphorylation of high molecular weight insulin receptor substrate proteins $(B$ and $C$ ). (A) Fao cells were stimulated with $100 \mathrm{nM}$ insulin or the $4 \times$ complete amino acid mixture for the indicated time $(\mathrm{min})$; lysates were separated by SDS-PAGE and immunoblotted with antiphosphotyrosine antibodies. (B) Antiphosphotyrosine immunoblot of antiphosphotyrosine immunoprecipitates from cells stimulated with in-

\section{Discussion}

A prominent feature of non-insulin-dependent diabetes mellitus (NIDDM) is insulin resistance in skeletal muscle, adipose tissue, and liver. At a cellular level, studies of insulin action in insulin-resistant animals and humans have demonstrated a variety of defects in insulin action, including decreased insulin receptor phosphorylation, decreased insulin receptor substrate phosphorylation, and decreased activation of glycogen synthase. However, specific genetic defects which could account for the observed insulin resistance in the majority of patients with NIDDM have not been identified thus far, suggesting that acquired alterations in insulin action play a critical role in the pathogenesis and maintenance of insulin resistance.

The availability of substrates for cellular energy production is important in the regulation of a variety of cellular and metabolic processes, and, in particular, in determining a given cell or tissue's response to hormonal stimulation. This has been demonstrated clearly in the case of insulin action. For example, the infusion of fatty acids has been shown to decrease insulin-stimulated glucose transport, primarily by inhibiting glucose oxidation, and, to a lesser extent, by inhibiting glycogen synthesis and stimulating gluconeogenesis (Randle hypothesis; reference 37). Sustained hyperglycemia, as is seen with NIDDM, can reduce insulin receptor kinase activity, possibly

sulin and/or amino acids for $30 \mathrm{~min}$. The position of the insulin receptor and high molecular weight IRS proteins (IRS-1 and -2) is indicated by the arrows. (C) Quantitation of inhibition of insulin-stimulated insulin receptor substrate phosphorylation by amino acids. Data are expressed as phosphorylation relative to insulin-stimulated cells (assigned value of one) and are derived from four independent experiments.






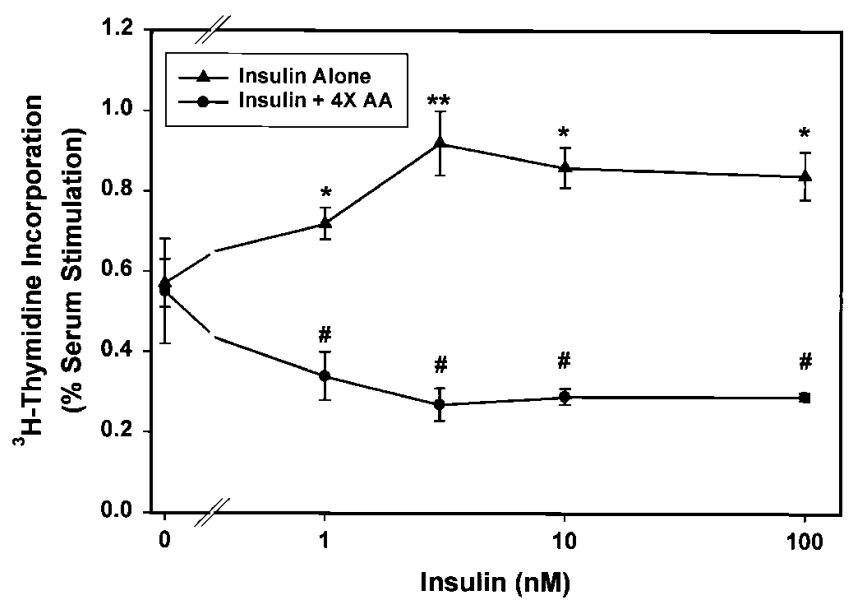

Figure 10. Amino acids inhibit insulin-stimulated mitogenesis. After a 24-h fast, Fao cells were treated for $18 \mathrm{~h}$ with $10 \% \mathrm{FBS}$, insulin alone, amino acids alone, or insulin plus amino acids and $\left[{ }^{3} \mathrm{H}\right]$ thymidine incorporation was measured. Data are normalized for protein content and expressed relative to serum-stimulated cells (assigned value of one). Data are the mean of two independent experiments, each performed in triplicate. ${ }^{*} P<0.01$; ${ }^{\#} P<0.001$ for amino acids plus insulin as compared with insulin alone.

by activating protein kinase $\mathrm{C}$ and increasing serine phosphorylation of the insulin receptor or its primary cytoplasmic substrate IRS-1, and decrease GLUT4 expression, thereby contributing to insulin resistance (glucotoxicity; reference 38). An additional level of complexity in substrate regulation of insulin action was identified by Marshall et al. (39), who found that amino acids enhanced glucose-induced desensitization of insulin-stimulated glucose transport in adipocytes. Further experiments demonstrated that glutamine was responsible for this effect of amino acids, via its entry into the hexosamine pathway. Glucosamine, a compound also known to enter the hexosamine pathway, also induces insulin resistance (40).

Numerous metabolic studies have provided another example of the specific modulation of insulin action by amino acids. These include stimulatory effects on protein synthesis and inhibitory effects on proteolysis and insulin-stimulated glucose metabolism $(2,6,7,10-15,41-44)$. These data demonstrate novel cellular mechanisms for these physiologic findings. Thus, amino acids enhance the effect of insulin to stimulate two key intermediates in the initiation of protein translation, p70 S6 kinase and PHAS-I, while inhibiting the effect of insulin on tyrosine phosphorylation of insulin receptor substrates and activation of PI 3-kinase, important upstream elements in pathways leading to insulin-stimulated glucose metabolism.

p70 S6 kinase and PHAS-I have been identified as important elements in the signal transduction pathways responsible for the regulation of protein synthesis and proteolysis (22). p70 S6 kinase phosphorylation of ribosomal protein S6 correlates with increases in translation, and ribosomes containing phosphorylated S6 are more likely to be found in polyribosomes engaged in translation (22). S6 phosphorylation also correlates with inhibition of autophagic proteolysis, suggesting that these processes are controlled by the same signal transduction pathway (17). PHAS-I (also known as 4E-BP1) is a phosphoprotein involved in regulation of the eIF-4E initiation factor complex. In the basal state, PHAS-I inhibits initiation of translation. The phosphorylation of PHAS-I in response to insulin or other growth factors permits dissociation of the complex, increased binding of eIF-4G to eIF-4E, and efficient initiation of translation $(27,45)$. The reduction in PHAS-I phosphorylation in insulin-deficient diabetic rats is likely to contribute significantly to the observed reduction in protein synthesis in diabetes (46).

Both p70 S6 kinase activation and PHAS-I phosphorylation are inhibited by rapamycin, placing them downstream of another potential regulatory element, mTor (also known as FRAP and RAFT1; references 47 and 48). The exact roles of these rapamycin-dependent pathways in protein metabolism remain unclear. Microinjection of anti-p70 S6 kinase antibodies into fibroblasts inhibits serum-stimulated protein synthesis by $\sim 90 \%$ (49). Inhibition of p70 S6 kinase by rapamycin inhibits S6 phosphorylation in vivo and has been shown to stimulate proteolysis and partially relieve the inhibitory effect of amino acids on proteolysis (17). Concurrent with its inhibition of p70 S6 kinase, rapamycin decreases recruitment of 80 S ribosomes into actively translating polysomes; however, rapamycin's inhibition of global protein synthesis varies from $10-70 \%$, depending on the cell type (17, 50-52). Rapamycin's effect on protein synthesis is also largely selective for inhibition of translation of mRNA containing $5^{\prime}$ polypyrimidine tracts. This includes mRNAs whose translation is regulated at the initiation phase, such as several elongation factors, ribosomal proteins, and growth-regulated proteins $(22,51,53)$.

Our finding that amino acids stimulate phosphorylation and activation of both p70 S6 kinase and PHAS-I in a rapamycin-dependent manner in cultured cells correlates well with physiologic data demonstrating a significant effect of amino acids on protein synthesis in vivo (16). While increased availability of amino acids might be expected to increase protein synthesis solely by means of increased substrate, several lines of evidence suggest an alternative mechanism. Firstly, amino acid stimulation of protein synthesis in isolated hepatocytes is mediated via modulation of translation initiation at the level of formation of the $40 \mathrm{~S}$ initiation complex (6); our data demonstrate a potential cellular mechanism for these effects. Secondly, we observe that branched chain amino acids play the dominant role in mediating activation of p70 S6 kinase and PHAS-I. These data are also consistent with physiologic data that have highlighted a distinct role for branched chain amino acids in the inhibition of proteolysis and stimulation of protein synthesis $(6,7)$. Our findings are also in agreement with Blommart et al. (17) who found that a mixture of leucine, tyrosine, and phenylalanine (three of the regulatory amino acids that inhibit proteolysis as well as a complete amino acid mixture) stimulated S6 phosphorylation and inhibited proteolysis in freshly isolated hepatocytes. The specificity of amino acid stimulation of these processes suggest that the effect of amino acids in vivo and in vitro is unlikely to be mediated solely by increased availability of amino acid substrates for protein synthesis or increased cellular levels of ATP resulting from amino acid metabolism.

The role of PI 3-kinase in protein metabolism is also complex. Wortmannin inhibits the stimulation of general protein synthesis by insulin, as well as the activation of Akt, p70 S6 kinase, and PHAS-I by growth factors or insulin, indicating that all of these are at least partially dependent upon activation of PI 3-kinase or a related kinase $(28,53)$. Our observation that 
wortmannin also inhibits amino acid-induced stimulation of p70 S6 kinase is of interest, since amino acids do not stimulate phosphotyrosine- or p85-associated PI 3-kinase, but rather inhibit both the basal and insulin-stimulated PI 3-kinase activity. In addition, we were unable to detect any 3-phosphorylated phosphoinositol products by HPLC after amino acid stimulation in ${ }^{32} \mathrm{P}$-labeled cells, indicating that the PI 3-lipid kinase is not involved. Thus, the effect of wortmannin on amino acid stimulation of p70 S6 kinase and PHAS-I phosphorylation may reflect the effect of this agent to inhibit amino acid transport into the cells (54), mTor kinase activity (24), or another protein or phosphoinositol kinase (55).

The finding that ketoisocaproic acid, the product of intracellular transamination of leucine, can also stimulate p70 S6 kinase supports the hypothesis that intracellular metabolism of amino acids is required for the effect on S6 kinase. However, transamination of leucine in the liver is limited, and our data do not exclude the possibility that the effects of branched chain amino acids are mediated at the cell surface, perhaps via a specific membrane receptor which may also recognize branched chain ketoacids. Mortimore et al. (30) have demonstrated that isovaleryl-L-carnitine and other leucine analogues mimic leucine's regulatory effects on proteolysis, and that Leu8-MAP, an octaleucine derivative that is nontransportable, inhibits autophagic proteolysis with a $K_{\mathrm{m}}$ equal to that of leucine, suggesting the presence of a leucine receptor on the cell surface. A photoreactive Leu8-MAP analogue also binds specifically to a membrane protein in isolated rat hepatocytes (56); however, further characterization of this potential binding site has not been completed. Additional studies will be required to clarify the requirement for transport, transamination, decarboxylation, and subsequent metabolism of specific amino acids in mediating the observed effects of amino acids on p70 S6 kinase and PHAS-I activation in specific tissue and cell types.

Thus, our data suggest that amino acids, particularly branched chain amino acids or their metabolites, may be exerting their effects on signal transduction at specific sites and implicate a novel mechanism by which amino acids or their metabolites can interface with hormone-dependent signal transduction pathways important for protein metabolism. Phosphotyrosine immunoblots of amino acid-stimulated cells demonstrate no independent effect of amino acids on tyrosine phosphorylation and suggest that the effects of amino acids are likely to be mediated by serine/threonine kinases upstream of p70 S6 kinase and PHAS-I. Future studies will be directed at elucidating the specific kinase(s) responsible for these effects of amino acids.

The effects of amino acids to modulate insulin action on glucose transport and gluconeogenesis have been well documented in metabolic studies $(10-15,43,44)$. High protein diets are also associated with glucose intolerance (57-59). In one study, increasing levels of protein in the diet resulted in increased fasting glucose concentrations and increased basal rates of hepatic glucose production, while glucose use during a hyperinsulinemic-euglycemic clamp was reduced by $20 \%$ in rats fed a high protein diet compared with the low protein diet (57). In addition, hepatic glucose production was only partially suppressed by insulin in the high-protein diet groups. Taken together, these data indicate that amino acids downregulate insulin action on glucose metabolism in vivo. Our data indicate a potential cellular mechanism for these observations, namely that amino acids inhibit critical early steps in postreceptor insulin action, including tyrosine phosphorylation of insulin receptor substrates IRS- 1 and IRS- 2 and binding of SH2 domain-containing proteins such as the regulatory subunit of PI 3-kinase, and decreased PI 3-kinase activity. These effects are clearly demonstrated in cell culture models from two important insulin target tissues. The inhibition of insulin-stimulated PI 3-kinase in Fao hepatoma cells and L6 myotubes are of potential physiologic importance, given the prominent role of PI 3-kinase-dependent pathways in regulation of hepatic gluconeogenesis (32) and glycogen synthesis (33) and in insulinstimulated glucose transport in muscle $(23,31)$.

It is interesting that the inhibitory effects of amino acids also extend to insulin-stimulated thymidine incorporation, demonstrating that amino acids also affect downstream events in insulin signaling critical for cell growth. The lack of effect of amino acids on basal (insulin-independent) mitogenesis also parallels closely the data for phosphorylation and PI 3-kinase activation and supports a role for amino acids to directly modulate insulin signaling to various PI 3-kinase-dependent pathways.

Whether these inhibitory effects of amino acids result from activation of serine/threonine kinases that phosphorylate insulin receptor substrates and diminish their suitability as substrates for the insulin receptor, as has been shown with TNF$\alpha$-induced insulin resistance (60), or are due to activation of protein tyrosine phosphatases, is unclear. The observation that the magnitude of inhibition of insulin-stimulated PI 3-kinase exceeds that of tyrosine phosphorylation of IRS-1 and IRS-2 may be related to an additional direct effect of amino acids on PI 3-kinase enzymatic activity (i.e., recruitment of an inhibitor to the enzyme complex). Finally, amino acids and/or products of their metabolism may result in the activation of other pathways which interface with the insulin signaling cascade. For example, recent data have demonstrated the importance of crosstalk between insulin and $G$ protein-coupled signaling pathways, including angiotensin II (61). Transgenic mice with reduced levels of the inhibitory $G$ protein $G_{i \alpha 2}$ also develop insulin resistance with decreased IRS-1 phosphorylation and increased protein tyrosine phosphatase activity (62).

Taken together, our data provide evidence for a bidirectional modulation of insulin action by amino acids on signaling to both protein and glucose metabolism. Importantly, these data from cultured cell models of two insulin-sensitive tissues provide clues as to the mechanisms which underlie the observed physiologic role for amino acids in maintenance of protein mass and inhibition of insulin's effects on glucose transport and gluconeogenesis. Elucidation of this interface or crosstalk between nutritional/metabolic signals and classical hormonal signal transduction cascades will likely yield new information regarding both insulin action and metabolic/biochemical pathways and may suggest mechanisms for dietary and/or pharmacologic manipulations that might improve insulin action in NIDDM and other states of insulin resistance.

\section{Acknowledgments}

The authors acknowledge the assistance of Dr. Bentley Cheatham for helpful discussions and assistance with lipid extraction experiments.

M.-E. Patti was supported by the Mary K. Iacocca Fellowship and a grant from the Boston Obesity and Nutrition Research Center (NIDDK P30 DK46200). C.R. Kahn was supported by National Insti- 
tutes of Health grant DK 33201 and the Diabetes Education and Research Center grant. E. Brambilla and L. Luzi were supported by Juvenile Diabetes Foundation International grant 194153.

\section{References}

1. Gerich, J., M. Haymond, and R. Rizza. 1981. Hormonal and substrate determinants of hepatic glucose production in man. In The Regulation of Carbohydrate Formation and Utilization in Mammals. C. Veneziale, editor. University Park Press, Baltimore, MD. 419-457.

2. Tessari, P., R. Barazzoni, M. Zanetti, E. Kiwanuka, and A. Tiengo. 1996. The role of substrates in the regulation of protein metabolism. Bailliere's Clin. Endocrinol. Metab. 10:511-532.

3. Kimball, S.R., M. Yancisin, R.L. Horetsky, and L.S. Jefferson. 1996. Translational and pretranslational regulation of protein synthesis by amino acid availability in primary cultures of rat hepatocytes. Int. J. Biochem. Cell Biol. 28: 285-294

4. Casetellino, P., L. Luzi, D.C. Simonson, M. Haymond, and R.A. DeFronzo. 1987. Effect of insulin and plasma amino acid concentrations on leucine metabolism in man. Role of substrate availability on estimates of whole body protein synthesis. J. Clin. Invest. 80:1784-1793.

5. Bier, D.M. 1989. Intrinsically difficult problems: the kinetics of body proteins and amino acids in man. Diabetes Metab. Rev. 5:111-132.

6. May, M.E., and M.G. Buse. 1989. Effects of branched-chain amino acids on protein turnover. Diabetes Metab. Rev. 5:227-245.

7. Louard, R.J., E.J. Barrett, and R.A. Gelfand. 1995. Overnight branchedchain amino acid infusion causes sustained suppression of muscle proteolysis. Metabolism. 44:424-429.

8. Goldberg, A.L., and R. Odessey. 1972. Oxidation of amino acids by diaphragms from fed and fasted rats. Am. J. Physiol. 223:1384-1391.

9. Buse, M.G., J.F. Biggers, K.H. Friderici, and J.F. Buse. 1972. Oxidation of branched chain amino acids by isolated hearts and diaphragms of the rat. The effect of fatty acids, glucose, and pyruvate respiration. J. Biol. Chem. 247: 8085-8096.

10. Flakoll, P.J., L.S. Wentzel, D.E. Rice, J.O. Hill, and N.N. Abumrad. 1992. Short-term regulation of insulin-mediated glucose utilization in four-day fasted human volunteers: role of amino acid availability. Diabetologia. 35: $357-366$.

11. Buckspan, R., B. Hoxworth, E. Cersosimo, J. Devlin, E. Horton, and N. Abumrad. 1986. $\alpha$-ketoisocaproate is superior to leucine in sparing glucose utilization in humans. Am. J. Physiol. 251:E648-E653

12. Tappy, L., K. Acheson, S. Normand, D. Schneeberger, A. Thelin, C. Pachiaudi, J.P. Riou, and E. Jequier. 1992. Effects of infused amino acids on glucose production and utilization in healthy human subjects. Am. J. Physiol. 262: E826-E833

13. Abumrad, N.N., R.P. Robinson, B.R. Gooch, and W.W. Lacy. 1982. The effect of leucine infusion on substrate flux across the human forearm. J. Surg. Res. 32:453-463.

14. Pisters, P.W.T., N.P. Restifo, E. Cersosimo, and M.F. Brennan. 1991. The effects of euglycemic hyperinslinemia and amino acid infusion on regional and whole body glucose disposal in man. Metabolism. 40:59-65.

15. Ferrannini, E., S. Bevilacqua, L. Lanzone, R. Bonadonna, L. Brandi, M. Oleggini, C. Boni, G. Buzzigoli, D. Ciociaro, L. Luzi, and R.A. DeFronzo. 1988. Metabolic interactions of amino acids and glucose in healthy humans. Diabetes Nutr. Metab. 3:175-186.

16. Brambilla, E., M.E. Patti, I. Terruzzi, and L. Luzi. 1996. Amino acids (AA) stimulate protein anabolism via p70 S6 kinase phosphorylation. Diabetes. 45:165A(Abstr.)

17. Blommaart, E.F.C., J.J.F.P. Luiken, P.J.E. Blommaart, G.M. van Woerkom, and A.J. Meijer. 1995. Phosphorylation of ribosomal protein S6 is inhibitory for autophagy in isolated rat hepatocytes. J. Biol. Chem. 270:23202326.

18. Chen, R.-H., and J. Blenis. 1990. Identification of Xenopus S6 protein kinase homologs (pp90rsk) in somatic cells: phosphorylation and activation during initiation of cell proliferation. Mol. Cell. Biol. 10:3204-3215.

19. Folli, F., M.J.A. Saad, J.M. Backer, and C.R. Kahn. 1993. Regulation of phosphatidylinositol 3-kinase activity in liver and muscle of animal models of insulin-resistant and insulin-deficient diabetes mellitus. J. Clin. Invest. 92:17871794.

20. Kyriakis, J.M., P. Banerjee, E. Nikolakaki, T. Dai, E.A. Rubie, M.F. Ahmad, J. Avruch, and J.R. Woodgett. 1994. The stress-activated protein kinase subfamily of c-Jun kinases. Nature. 369:156-160.

21. Downward, J. 1994. Regulating S6 kinase. Nature. 371:378-379.

22. Brown, E.J., and S.L. Schreiber. 1996. A signaling pathway to translational control. Cell. 86:517-520.

23. Chung, J., T.C. Grammer, K.P. Lemon, A. Kazlauskas, and J. Blenis. 1994. PDGF- and insulin-dependent pp70S6k activation mediated by phosphatidylinositol-3-OH kinase. Nature. 370:71-75.

24. Brunn, G.J., J. Williams, C. Sabers, G. Wiederrecht, J.C. Lawrence, Jr., and R.T. Abraham. 1996. Direct inhibition of the signaling functions of the mammalian target of rapamycin by the phosphoinositide 3-kinase inhibitors, wortmannin and LY294002. EMBO (Eur. Mol. Biol. Organ.) J. 15:5256-5267.

25. Bergering, B.M., and P.J. Coffer. 1995. Protein kinase B (c-Akt) in phosphatidylinositol-3-OH kinase signal transduction. Nature. 376:599-602.

26. Andjelkovic, M., T. Jakubowicz, P. Cron, X.F. Ming, J.W. Han, and B.A. Hemmings. 1996. Activation and phosphorylation of a pleckstrin homology domain containing protein kinase (RAC-PK/PKB) promoted by serum and protein phosphatase inhibitors. Proc. Natl. Acad. Sci. USA. 93:5699-5704.

27. Pause, A., G.J. Belsham, A. Gingras, O. Donze, T. Lin, J.C. Lawrence, Jr., and N. Sonenberg. 1994. Insulin-dependent stimulation of protein synthesis by phosphorylation of a regulator of 5'-cap function. Nature. 371:762-767.

28. Lin, T.A., X. Kong, A.R. Saltiel, P.J. Blackshear, and J.C. Lawrence, Jr. 1995. Control of PHAS-I by insulin in 3T3-L1 adipocytes. J. Biol. Chem. 270: $18531-18538$.

29. Tessari, P. 1994. Effects of insulin on whole-body and regional amino acid metabolism. Diab. Metab. Rev. 10:253-285.

30. Miotto, G., R. Venerando, K.K. Khurana, N. Siliprandi, and G.E. Mortimore. 1992. Control of hepatic proteolysis by leucine and isovaleryl-L-carnitine through a common locus: evidence for a possible mechanism of recognition at the plasma membrane. J. Biol. Chem. 267:22066-22072.

31. Katagiri, H. T. Asano, H. Ishihara, K. Inukai, Y. Shibasaki, M. Kikuchi, Y. Yazaki, and Y. Oka. 1996. Overexpression of catalytic subunit p110 $\alpha$ of phosphatidylinositol 3kinase increases glucose transport activity with translocation of glucose transporters in 3T3-L1 adipocytes. J. Biol. Chem. 271:1698716990.

32. Sutherland, C., R.M. O'Brien, and D.K. Granner. 1995. Phosphatidylinositol 3-kinase, but not p70/p85 ribosomal S6 protein kinase, is required for the regulation of phosphoenolpyruvate carboxykinase (PEPCK) gene expression by insulin. J. Biol. Chem. 270:15501-15506.

33. Yamamoto-Honda, R., K. Tobe, Y. Kaburagi, K. Ueki, S. Asai, M. Yachi, M. Shirouzu, J. Yodoi, Y. Akanuma, S. Yokoyama, et al. 1995. Upstream mechanisms of glycogen synthase activation by insulin and insulin-like growth factor-I. Glycogen synthase activation is antagonized by wortmannin or LY294002 but not by rapamycin or by inhibiting p21ras. J. Biol. Chem. 270: 2729-2734.

34. Elmendorf, J.S., A. Damrau-Abney, T.R. Smith, T.S. David, and J. Turinsky. 1995. Insulin-stimulated phosphatidylinositol 3-kinase activity and 2-deoxyD-glucose uptake in rat skeletal muscle. Biochem. Biophys. Res. Commun. 208: 1147-1153.

35. Okada, T., Y. Kawano, T. Sakakibara, O. Hazeki, and M. Ui. 1994. Essential role of phosphatidylinositol 3-kinase in insulin-induced glucose transport and antilipolysis in rat adipocytes: studies with a selective inhibitor wortmannin. J. Biol. Chem. 269:3568-3573.

36. Cheatham, B., C.J. Vlahos, L. Cheatham, L. Wang, J. Blenis, and C.R. Kahn. 1994. Phosphatidylinositol 3-kinase activation is required for insulin stimulation of pp70 66 kinase DNA synthesis and glucose transporter translocation. Mol. Cell. Biol. 14:4902-4911.

37. Ferrannini, E., E.J. Barrett, S. Bevilacqua, and R.A. DeFronzo. 1983. Effect of fatty acids on glucose production and utilization in man. J. Clin. Invest. 72:1737-1747

38. Chin, J.E., M. Dickens, J.M. Tavare, and R.A. Roth. 1993. Overexpression of protein kinase $\mathrm{C}$ isoenzymes alpha, beta I, gamma, and epsilon in cells overexpressing the insulin receptor. Effects on receptor phosphorylation and signaling. J. Biol. Chem. 268:6338-6347.

39. Traxinger, R.R., and S. Marshall. 1989. Role of amino acids in modulating glucose-induced desensitization of the glucose transport system. J. Biol. Chem. 264:20910-20916

40. Rossetti, L., M. Hawkins, W. Chen, J. Gindi, and N. Barzilai. 1995. In vivo glucosamine infusion induces insulin resistance in normoglycemic but not in hyperglycemic conscious rats. J. Clin. Invest. 96:132-133.

41. Garlick, P.J., and I. Grant. 1988. Amino acid infusion increases the sensitivity of muscle protein synthesis in vivo to insulin. Biochem. J. 254:579-584.

42. Wahren, J. 1992. Role of branched-chain amino acids in protein metabolism. In Branched Chain Amino Acids: Biochemistry, Physiopathology, and Clinical Science. P. Schauder and et al., editors. Raven Press, Ltd., New York. $1-7$

43. Flakoll, P.J., M. Kulaylat, M. Frexes-Steed, J.O. Hill, and N.N. Abumrad. 1991. Amino acids enhance insulin resistance to exogenous glucose infusion in overnight-fasted humans. J. Parenter. Enteral Nutr. 15:123-127.

44. Abumrad, N.N., S. Helou, P. Molina, and P.J. Flakoll. 1992. Regulation by amino acids of glucose utilization in humans. In Branched Chain Amino Acids: Biochemistry, Physiopathology, and Clinical Science. P. Schauder and et al., editors. Raven Press, Ltd., New York. 9-19.

45. Kimball, S.R., C. Jurasinski, J.C. Lawrence, Jr, and L.S. Jefferson. 1997. Insulin stimulates protein synthesis in skeletal muscle by enhancing the association of eIF-4E and eIF-4G. Am. J. Physiol. 272:C754-C759.

46. Kimball, S.R., L.S. Jefferson, P. Fadden, T.A.J. Haystead, and J.C. Lawrence, Jr. 1996. Insulin and diabetes cause reciprocal changes in the association of eIF-4E and PHAS-I in rat skeletal muscle. Am. J. Physiol. 270:C705C709.

47. Brown, E.J., M.W. Albers, T.B. Shin, K. Ichikawa, C.T. Keith, W.S Lane, and S.L. Schreiber. 1994. A mammalian protein targeted by G1-arresting 
rapamycin-receptor complex. Nature. 369:756-758.

48. Brown, E.J., P.A. Beal, C.T. Keith, J. Chen, T.B. Shin, and S.L. Schreiber. 1995. Control of p70 S6 kinase by kinase activity of FRAP in vivo. Nature. 377:441-446.

49. Lane, H.A., A. Fernandez, N.J.C. Lamb, and G. Thomas. 1993. p70 function is essential for G1 progression. Nature. 363:170-172.

50. Jefferies, H.B.J., C. Reinhard, S.C. Kozma, and G. Thomas. 1995. Rapamycin selectively represses translation of the "polypyrimidine tract" mRNA family. Proc. Natl. Acad. Sci. USA. 91:4441-4445.

51. Terada, N., K. Patel, K. Takase, K. Kohno, and A.C. Nairn. 1995. Rapamycin selectively inhibits translation of mRNAs encoding elongation factors and ribosomal proteins. Proc. Natl. Acad. Sci. USA. 91:11477-11481.

52. Giasson, E., and S. Meloche. 1995. Role of p70 S6 protein kinase in angiotensin II-induced protein synthesis in vascular smooth muscle cells. J. Biol. Chem. 270:5225-5231.

53. Mendez, R., M.G. Myers, Jr., M.F. White, and R.E. Rhoads. 1996. Stimulation of protein synthesis, eukaryotic translation initiation factor $4 \mathrm{E}$ phosphorylation, and PHAS-1 phosphorylation by insulin requires insulin receptor substrate-1 and phosphotidylinositol-3-kinase. Mol. Cell. Biol. 16:2857-2864.

54. Tsakiridis, T., H.E. McDowell, T. Walker, C.P. Downes, H.S. Hundal, M. Vranic, and A. Klip. 1995. Multiple roles of phosphatidylinositol 3-kinase in regulation of glucose transport, amino acid transport, and glucose transporters in L6 skeletal muscle cells. Endocrinology. 136:4315-4322.

55. Nakanishi, S., K.J. Catt, and T. Balla. 1995. A wortmannin-sensitive phosphatidylinositol 4-kinase that regulates hormone-sensitive pools of inositolphospholipids. Proc. Natl. Acad. Sci. USA. 92:5317-5321.

56. Mortimore, G.E., Jr., J.J. Wert, G. Miotto, R. Venerando, and M. Kadowaki. 1994. Leucine-specific binding of photoreactive Leu Le $_{7}$ MAP to a high molecular weight protein on the plasma membrane of the isolated rat hepatocyte. Biochem. Biophys. Res. Commun. 203:200-208.

57. Rossetti, L., D.L. Rothman, R.A. DeFronzo, and G.I. Shulman. 1989. Effect of dietary protein on in vivo insulin action and liver glycogen repletion. Am. J. Physiol. 257:E212-E219.

58. Peret, J., S. Foustock, M. Chanez, B. Bois-Joyeux, and R. Assan. 1981. Plasma glucagon and insulin concentrations and hepatic phosphoenolpyruvate carboxykinase and pyruvate kinase activities during and upon adaptation of rats to a high protein diet. J. Nutr. 111:1173-1184.

59. Kettelhut, I.C., M.C. Foss, and R.H. Migliorini. 1980. Glucose homeostasis in a carnivorous animal (cat) and in rats fed a high-protein diet. Am. J. Physiol. 239:R437-R444.

60. Hotamisligil, G.S., A. Budavari, D. Murray, and B.M. Spiegelman. 1994.

Reduced tyrosine kinase activity of the insulin receptor in obesity-diabetes. Central role of tumor necrosis factor-alpha. J. Clin. Invest. 94:1543-1549.

61. Velloso, L.A., F. Folli, X.J. Sun, M.F. White, M.J.A. Saad, and C.R. Kahn. 1996. Cross-talk between the insulin and angiotensin signaling system. Proc. Natl. Acad. Sci. USA. 93:12490-12495.

62. Moxham, C.M., and C.C. Malbon. 1996. Insulin action impaired by deficiency of the G-protein subunit $\mathrm{G}_{\mathrm{i} \alpha 2}$. Nature. 379:840-843. 